\title{
CONSIDERATIONS ON THE ORIGIN OF THE OPHTHALMIC ARTERY FROM THE INTERNAL CAROTID ARTERY
}

\section{Vărgău Iulia', Bordei Petru', Ispas Viorel'1}

${ }^{1}$ University “Ovidius” of Constanţa, Faculty of Medicine

Viorel Ispas

Faculty of Medicine, Univeristy „, Ovidius” of Constanta, Universitatii Alee No. 1, Campus B, Constanta, Romania email:vyos@yahoo.com phone: +40723646371

\begin{abstract}
The study of CT angiographies performed on a CT scanner GE LightSpeed VCT16 Slice CT revealed some morphological features of the ophthalmic artery related to origin, morphometry and the internal carotid arteries in the vicinity of this artery. The diameter of the left internal carotid artery under the origin of the ophthalmic artery was between 4.0-5.8 $\mathrm{mm}$ and that of the right ophthalmic artery at the same level was between 4.1-5.3 mm. Under the origin of the ophthalmic artery, the internal carotid arteries were larger in diameter on the leftside in $80 \%$ of cases, with differences of 0.1-0.3 $\mathrm{mm}$, and on the right side these differences were between 0.1-0.2 mm, 20\% of cases. The diameter of the left internal carotid artery above the origin of the ophthalmic artery was 3.7-5.0 $\mathrm{mm}$, and the origin of the right carotid artery at the same level was 3.8-5.0 $\mathrm{mm}$.
\end{abstract}

Keywords: ophthalmic artery - origin, caliber

\section{Introduction}

"Neuroradiological imaging allows the visualization of the increasingly fine structures, with a precision close to that obtained by anatomical dissections. The ophthalmic artery is a difficult element to highlight because of its thin caliber, its sinuous tract and its multiple collateral branches that are very thin" (1).

The ophthalmic artery is the major collateral branch of the internal carotid and presents anastomoses with the external carotid system, which is performed by facial artery, temporal superficial and especially maxillary, anastomoses occurring at the orbit, nose, face and eyelid level $(1,2)$.

"It is a collateral branch of the cerebral part of the internal carotid artery, which is detached from the cranial surface of this artery, into the infraclinoidian $\mathrm{C} 2$ portion as soon as the ophthalmic artery exits from the cavernous sinus, the level where the internal carotid is goes posterior to give of its terminal branches (1-4). At the origin, the artery presents its first segment, the intracranial segment, who it is located in the anterior cranial fossa (the middle floor of the skull base) under the optic nerve. 


\section{Material and method}

Our results were obtained on CT angiography, performed on a GE LightSpeed VCT16 Slice CT computer tomograph, in the endowment of the "St. Andrei "in Constanta. There were recorded: the origin level and caliber of the ophthalmic artery, as well as the diameters of the internal carotid artery above and below the origin of the ophthalmic artery. The results obtained were compared to the right-left side to indicate the possible differences between the observed targets.

\section{Results}

The diameter of the left ophthalmic artery was between 1.2-1.7 $\mathrm{mm}$ and the diameter of the right ophthalmic artery ranged between 1.3-1.7 $\mathrm{mm}$. In $40 \%$ of cases, the right ophthalmic artery was larger than the left one with 0.1-0.4 mm, in $20 \%$ of cases the left ophthalmic artery was larger than the right ophthalmic artery with 0.4 $0.9 \mathrm{~mm}$, and in $40 \%$ of cases the two ophthalmic arteries had an equal caliber.

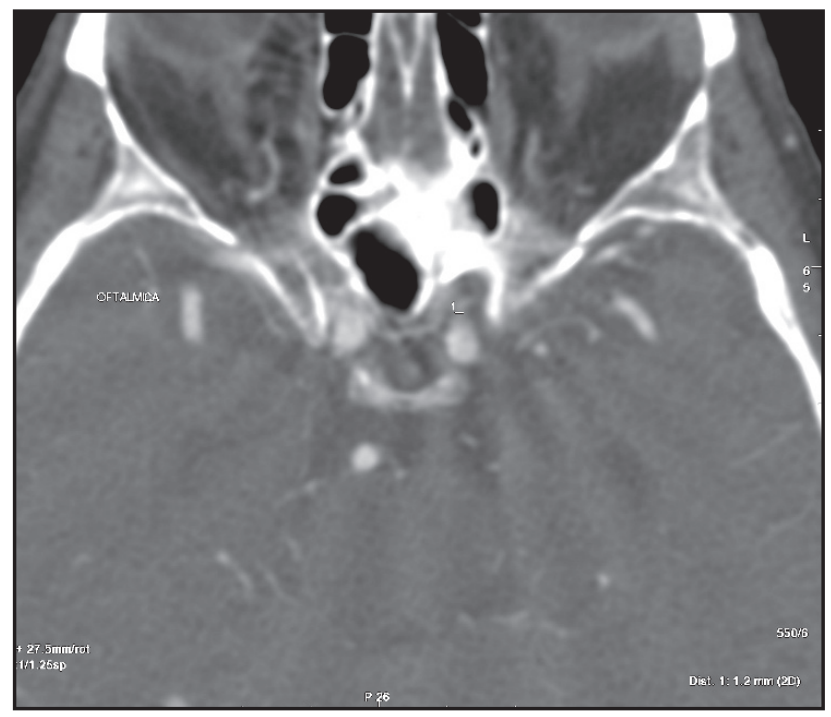

Figure 1 The diameter of the left ophthalmic artery is: 1.2 $\mathrm{mm}$

The origin of the ophthalmic artery from the left internal carotid artery related to its end was located at a distance of 11.6-15.9 $\mathrm{mm}$ and the origin of the right ophthalmic artery was located at a distance of 10.2-14.9 mm.

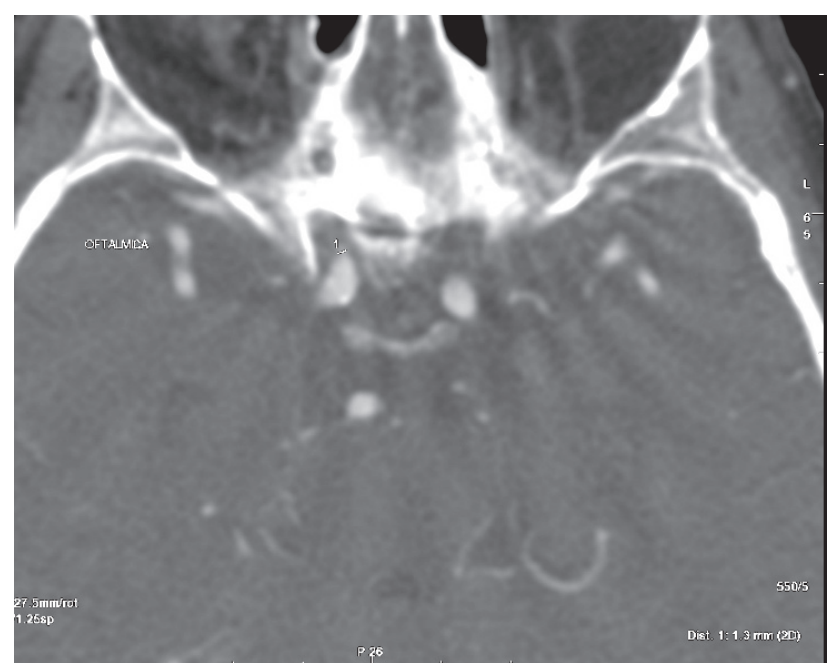

Figure 2 The diameter of the right ophthalmic artery is: $1.3 \mathrm{~mm}$

Compared to right-left, this distance was larger on the left by $0.9-1.4 \mathrm{~mm}$.

The diameter of the left internal carotid artery under the ophthalmic artery origin was between 4.0-5.8 $\mathrm{mm}$ and the ophthalmic right at the same level was between 4.1-5.3 mm.

Under the origin of the ophthalmic artery, the internal carotid arteries were larger in diameter on the left in $80 \%$ of cases, with differences of $0.1-0.3 \mathrm{~mm}$, and on the right these differences were between $0.1-0.2 \mathrm{~mm}$, in $20 \%$ of cases.

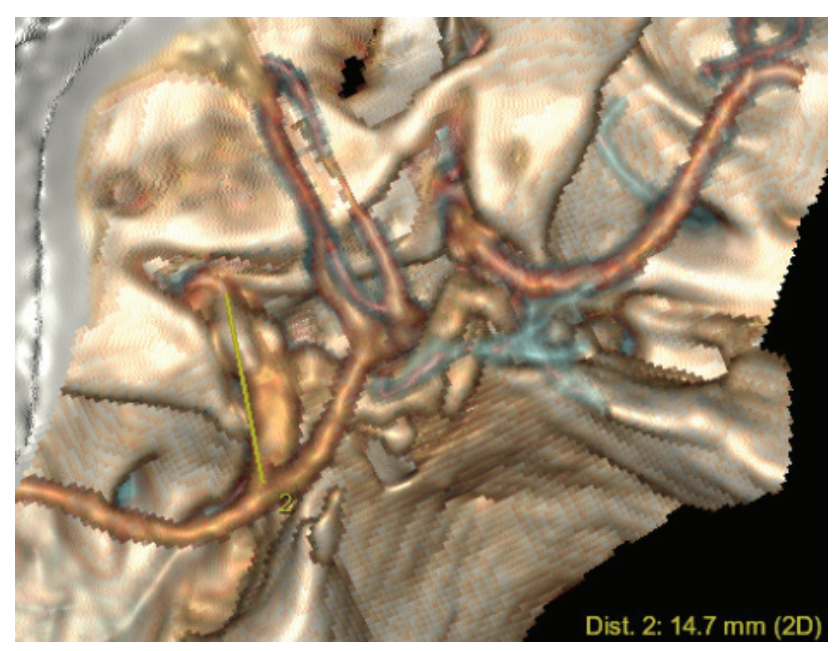

Figure 3 The distance between the origin of the left ophthalmic artery and the end of the internal carotid artery is $14.7 \mathrm{~mm}$.

The diameter of the left internal carotid artery above the origin of the ophthalmic artery was $3.7-5.0 \mathrm{~mm}$, and the origin of the right carotid artery at the same level was 3.8-5.0 $\mathrm{mm}$. 


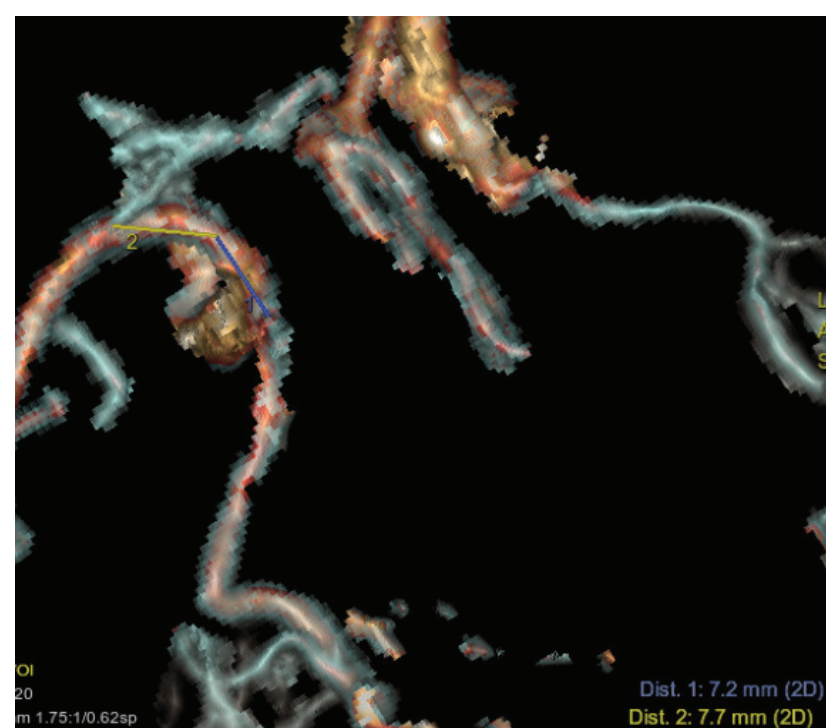

Figure 4 The distance between the origin of the right ophthalmic artery and the end of the internal carotid artery is $14.9 \mathrm{~mm}$.

Above the origin of the ophthalmic artery, the internal carotid arteries were larger in diameter on the left side in $25 \%$ of cases, with differences of 0.1-0.2 $\mathrm{mm}$, and on the right side these differences were between $0.1-0.3 \mathrm{~mm}$, in $20 \%$ of cases.

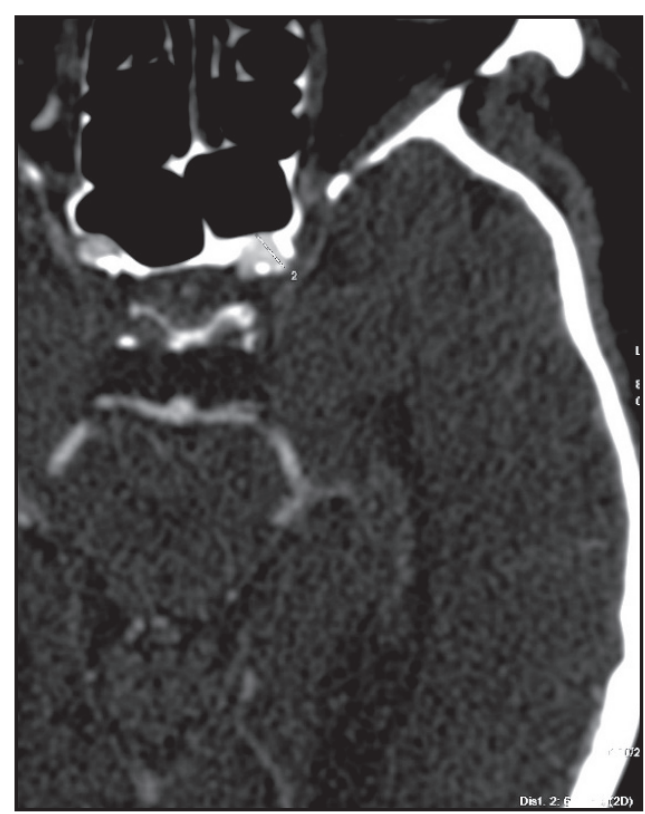

Figure 5 The diameter of the left internal carotid artery under the origin of the ophthalmic artery is $5.6 \mathrm{~mm}$.

Following the origin of the left ophthalmic artery, the internal carotid artery diameter decreases by $0.3-0.5 \mathrm{~mm}$, and at the right internal carotid artery with $0.3-0.6 \mathrm{~mm}$.

\section{Discussions}

After (1), "the fine analysis of the ophthalmic artery still requires some details, on origin, morphometry, and especially on its collateral branches."

Table 1. The ophthalmic artery diameter at the origin

\begin{tabular}{|l|r|}
\hline \multicolumn{1}{|c|}{ Author } & \multicolumn{1}{c|}{$\begin{array}{c}\text { The ophthalmic artery } \\
\text { diameter }\end{array}$} \\
\hline Bouchet & \multicolumn{1}{c}{$1.5 \mathrm{~mm}$} \\
\hline Ducasse & $\begin{array}{r}\text { M: } 1.54+/-0.04 \\
\text { F: } 1.31+/-0.05\end{array}$ \\
\hline Lang & $\begin{array}{r}\text { r. opht. art.: } 1.5-2.0 \mathrm{~mm} \\
\text { 1. opth. art.: } 1.0-2.0 \mathrm{~mm}\end{array}$ \\
\hline Jimenez & $\begin{array}{l}\text { r. opht. art.: } 1.3-1.7 \mathrm{~mm} \\
\text { 1. opth. art.: } 1.2-1.7 \mathrm{~mm}\end{array}$ \\
\hline Personal results &
\end{tabular}

We did not find the diameter of the ophthalmic artery more than $1.7 \mathrm{~mm}$, so smaller by $0.3 \mathrm{~mm}$ than $(2,3)$, but $0.2 \mathrm{~mm}$ larger than $(4,5)$. In the literature, only (6) mentions a 0.23 $\mathrm{mm}$ difference in male gender versus female gender. (5) finds the diameter of the right ophthalmic artery greater than the diameter of the left ophthalmic artery with differences of $0.3-0.8 \mathrm{~mm}$, in $58.33 \%$ of cases, in $41.67 \%$ of cases the two ophthalmic arteries having the same diameter. We found that only the minimum diameter of the right ophthalmic artery greater with $0.1 \mathrm{~mm}$, the maximum diameter of the ophthalmic artery having the same value on both arteries.

The diameter of the left internal carotid artery under the origin of the ophthalmic artery was found to be between 4.0-5.8 mm, (5) finding it between $5.5-8.5 \mathrm{~mm}$, between the extreme values finding a greater interval than us with $1.2 \mathrm{~mm}$. At the right internal carotid artery underneath the origin of the ophthalmic artery, we found a diameter between 4.1-5.3 $\mathrm{mm}$ (5), finding it between $5.0-8.5 \mathrm{~mm}$, between extreme values finding it bigger than us with $2.3 \mathrm{~mm}$. It is found that the diameters of the internal carotid arteries found by us are smaller than the values of the same diameters found by (5). 


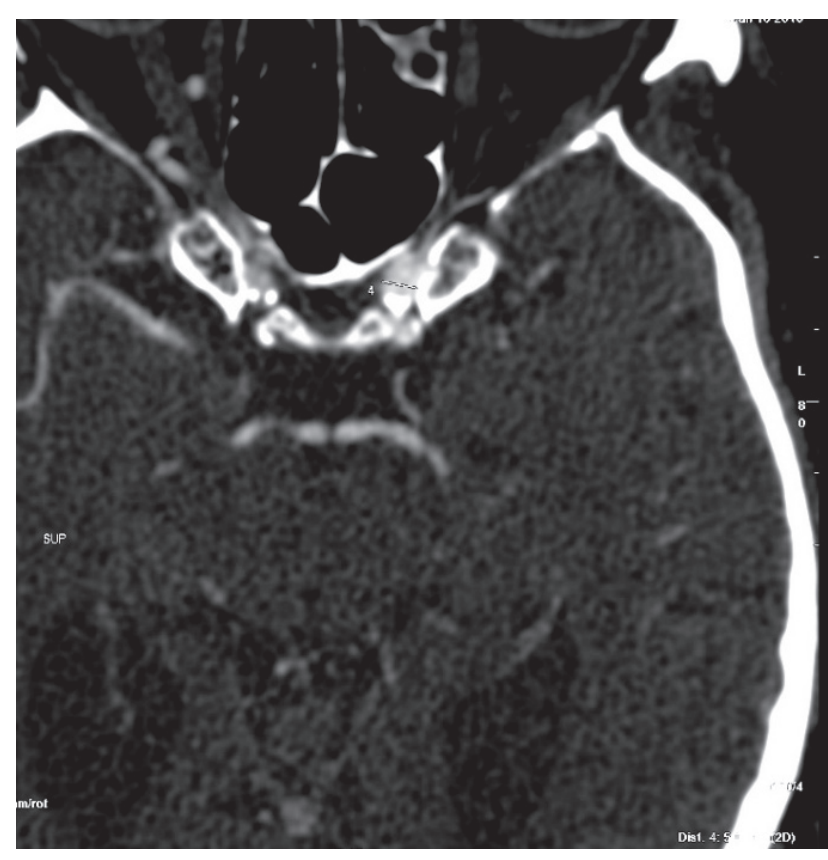

Figure 6 The diameter of the left internal carotid artery above the origin of the ophthalmic artery is $5.0 \mathrm{~mm}$.

The diameter of the left internal carotid artery above the origin of the ophthalmic artery was found to be between $3.7-7.0 \mathrm{~mm}$, (5) finding it between $3.0-7.0 \mathrm{~mm}$, between the extreme values finding a greater interval than us with 2.7 $\mathrm{mm}$.

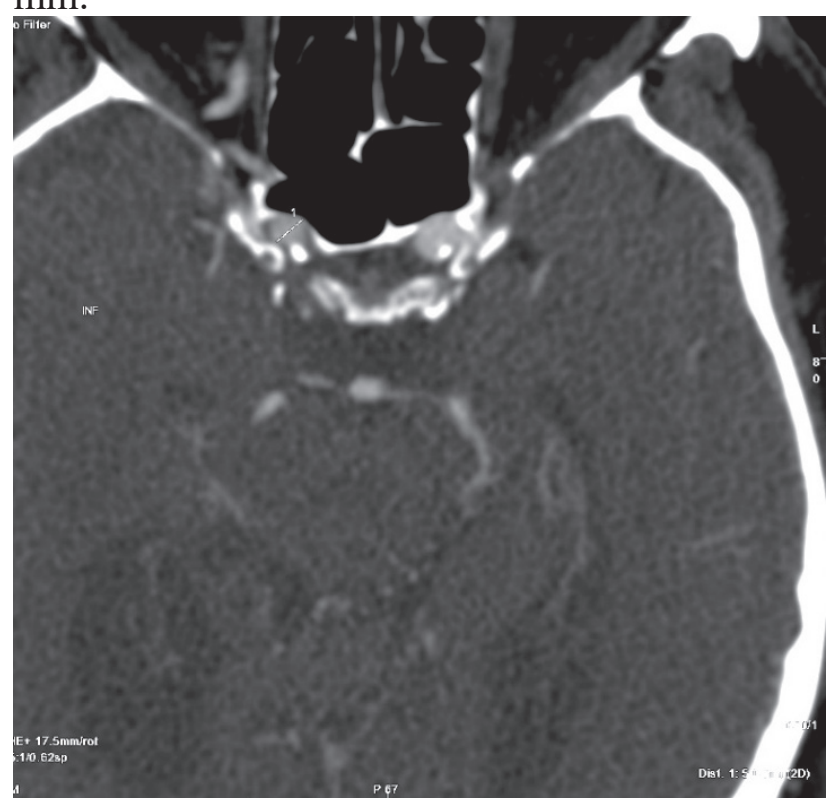

Figure 7 The diameter of the internal carotid artery under the origin of the ophthalmic artery is $5.3 \mathrm{~mm}$.

At the right internal carotid artery above the origin of the ophthalmic artery, we found a diameter between $3.8-5.3 \mathrm{~mm}$ (5), finding it between $3.0-6.5 \mathrm{~mm}$, between extreme values finding it bigger than us by $1.0 \mathrm{~mm}$.

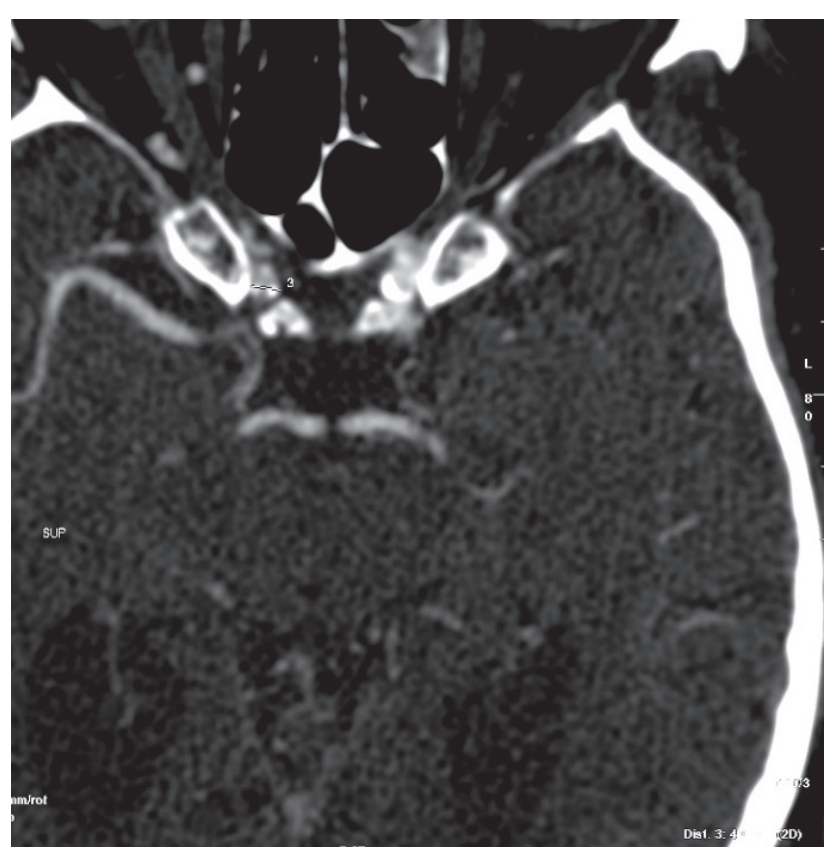

Figure 8 The diameter of the left internal carotid artery above the origin of the ophthalmic artery is $4.7 \mathrm{~mm}$.

It is found at both levels that above the origin of the ophthalmic artery, the diameters of internal carotid arteries found by us on both sides of the body are smaller than the values of the same diameters found by (5), except for the minimum values of these diameters, we found a higher value of 0.7-0.8 $\mathrm{mm}$.

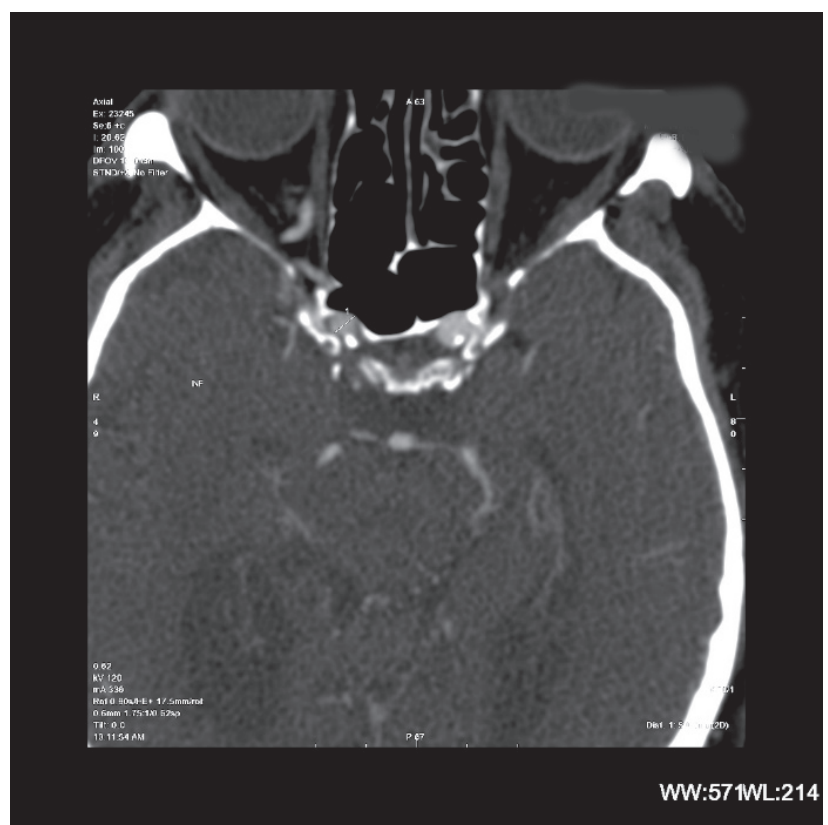

Figure 9 The diameter of the internal carotid artery under the origin of the ophthalmic artery is $5.3 \mathrm{~mm}$. 


\section{Conclusions}

The ophthalmic artery imagistics must be well-known because it requires reconstructions that can not be made without basic radioanatomy. The anastomotic systems between the ophthalmic artery and the external carotid artery branches (especially the middle meningeal artery) are important to be identified and condition the vascular pathology of this territory. There remains the election exploration for the study of the tract and anastomoses of the ophthalmic artery, which are essential in the clinic prior to the embolization of an aneurysm originating in the ophthalmic artery, which if the thrombosis happens, a countercurrent vascularization by the facial artery it is possible (1).

\section{References}

1. Raoul S, De Kersaint-Gilly A, Robert R, Lardoux MC, Armstrong O RJ. Étude radioanatomique de l'artère ophtalmique. In: Morphologie Bull Assoc Anat,. 1968. p. 146: 22-53.

2. Ducasse A. Les annexes du globe oculaire. În: Chevrel JP - Anatomie Clinique. Tête et Cou. Ed. Springer-Verlag, Paris. 1996. 185198 p.
3. Ducasse A. Vascularisation et innervation sensitive du contenu orbitaire. In: În: Chevrel JP - Anatomie Clinique Tête et Cou Ed Springer-Verlag, Paris. 1996. p. 199-203.

4. Ducasse A. Le globe oculaire (bulbe de l'œil). In: În: Chevrel JP - Anatomie Clinique Tête et Cou Ed Springer-Verlag, Paris. 1996. p. 185-98.

5. Jiménez-Castellanos J, Carmona A, Castellanos L, Catalina-Herrera C. Microsurgical anatomy of the human ophthalmic artery: a mesoscopic study of its origin, course and collateral branches. Surg Radiol Anat. Springer-Verlag; 1995 Jun;17(2):139-43.

6. Lang J, Kageyama I. The ophthalmic artery and its branches, measurements and clinical importance. Surg Radiol Anat. 1990;12(2):83-90. 